\title{
DEVELOPMENT OF A MULTILAYER MODIS IST-ALBEDO PRODUCT OF GREENLAND
}

\author{
D.K Hall', J.C. Comiso ${ }^{2}$, R.I. Cullather ${ }^{3}$, N.E. DiGirolamo ${ }^{4}$, S.M. Nowicki ${ }^{2}$ and B.C. Medley ${ }^{2}$, \\ ${ }^{1}$ Michigan State University, East Lansing, MI 48824 \\ ${ }^{2}$ NASA / Goddard Space Flight Center, Greenbelt, MD 20771 \\ ${ }^{3}$ University of Maryland, College Park, MD 20740 \\ ${ }^{4}$ SSAI, Lanham, MD 20706
}

\begin{abstract}
A new multilayer IST-albedo Moderate Resolution Imaging Spectroradiometer (MODIS) product of Greenland was developed to meet the needs of the ice sheet modeling community. The multiple layers of the product enable the relationship between IST and albedo to be evaluated easily. Surface temperature is a fundamental input for dynamical ice sheet models because it is a component of the ice sheet radiation budget and mass balance. Albedo influences absorption of incoming solar radiation. The daily product will combine the existing standard MODIS Collection-6 ice-surface temperature, derived melt maps, snow albedo and water vapor products. The new product is available in a polar stereographic projection in NetCDF format. The product will ultimately extend from March 2000 through the end of 2017.
\end{abstract}

Index Terms - Greenland, MODIS, IST, Albedo

\section{INTRODUCTION}

The rate of mass loss of the Greenland ice sheet has increased in recent decades due to increases in both ice discharge and surface meltwater runoff. It has been difficult to document these changes quantitatively based on in-situ measurements alone. Specifically, average air and surface temperature of the entire ice sheet are impossible to obtain due, at least in part, to the low density of meteorological stations on the ice sheet. Satellites can obtain accurate surface temperature measurements of the ice sheet though clouds usually preclude their ability to measure the entire ice sheet at one time [1,2].

Since early 2000 the Moderate Resolution Imaging Spectroradiometer (MODIS) instrument on the Terra satellite has been acquiring surface temperature measurements with an accuracy of $\sim 1^{\circ} \mathrm{C}$ over snow and ice. An ice-surface temperature (IST) product of Greenland was developed from the MOD29 standard MODIS product, creating an Environmental Data Record (EDR) of the surface temperature of the ice sheet [2]. In the present work, this EDR is being extended in time, and upgraded to include additional layers of information that are useful to modelers and climatologists.

The following Terra MODIS products are used in putting together the new multi-layer daily MODIS product of Greenland: MOD29 IST, MOD10 albedo and MOD05 water vapor. In addition, an ice sheet mask, developed by Howat et al. [5], is provided as another layer. The product is produced in NetCDF format in a polar stereographic projection. A sample day of the IST and melt layers is shown in Figure 1. The maps shown in Figure 1 are based on using all available swaths in a 24-hour period. For this sample day, 3 July 2012, there were 23 MODIS Terra swaths available to develop the daily products. 
Surface temperature is a fundamental input for dynamical ice sheet models $[3,4]$ because it is an important component of the ice sheet radiation budget and mass balance. The surface temperature of the ice sheet must be known for the estimation and modeling of surface mass balance (SMB) and ice sheet processes. Furthermore, runoff is largely controlled by surface temperature, and the IST affects basal melt and internal temperature of the ice sheet. To validate model output, in-situ or/and satellite-derived measurements must be compared with modeled surface temperature.

Water vapor in the atmosphere above Greenland can affect the accuracy of the IST retrievals. Thus we include a MODIS water vapor product as a data layer to enable further analysis of the accuracy of the IST.

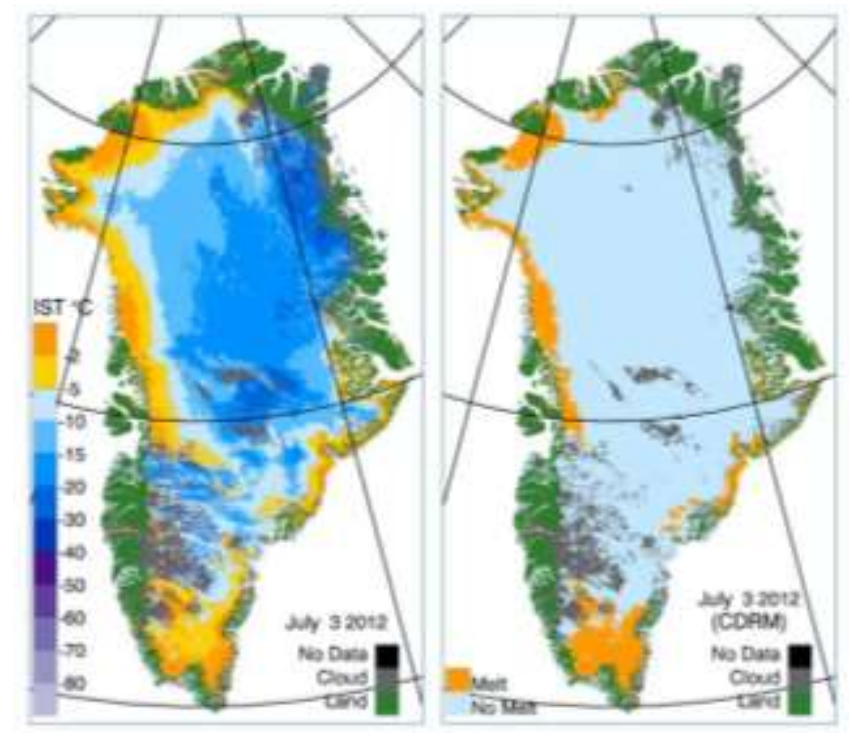

Figure 1. Collection 6 (C6) MODIS Terra IST (left) and derived melt (right) maps showing the result of using all available swaths in a given day to develop a daily product.

Ice sheet albedo is of also of great interest because a lowering of the albedo could indicate enhanced absorption of solar radiation possibly resulting in enhanced surface melting [6]. The amount of absorbed radiation influences the SMB and meltwater production of the Greenland ice sheet.

\section{CHARACTERISTICS OF THE MULTI- LAYER PRODUCT}

The new, multilayer IST-albedo product of Greenland is an advancement beyond the existing product described in Hall et al. [2]. Improvements include the following:

- MODIS Collection 6 (C6) data products are derived from the most-advanced version of the product algorithms;

- The spatial resolution of the new product is $0.8 \mathrm{~km}$ (vs. $1.6 \mathrm{~km}$ in the existing product);

- An improved ice mask [5] is included as a data layer;

- Four layers of daily geophysical information are available in the new product: IST, surface melt, albedo and water vapor;

- The daily maps of the new product are developed using all available swaths in a 24-hr period (vs. swaths in a 6-hr period focused on the warmest part of the day for the existing product).

\section{CONCLUSION AND DISCUSSION}

The multilayer IST-albedo product of Greenland was developed to meet the needs of the ice sheet modeling community. The multiple layers of the product will facilitate assessment of the relationship between IST and albedo. As ice sheet models become increasingly sophisticated, improved input data, and data for comparison of model results, is needed. This new product was designed to meet that need. The product will ultimately include all available swaths for the entire MODIS Terra record, from late-February 2000 through 2017.

The IST algorithm is a follow-on from the original IST algorithm developed by Key et al. [7] as modified for the MOD29 IST product. This same basic algorithm is in use for the Suomi-NPP 
Visible Infrared Imaging Radiometer Suite (VIIRS) IST product. Thus the decision to use IST for the new multilayer product was made to facilitate the development of an inter-satellite EDR and ultimately a climate-data record (CDR) beginning with the MODIS data in 2000 and continuing through the VIIRS era. This will facilitate the study of long-term changes in the surface temperature and albedo of the Greenland ice sheet both through modeling and observations.

\section{REFERENCES}

[1] J. C. Comiso, "Warming trends in the Arctic," Jour. Climate, vol. 16, pp. 3498-3510, 2003.

[4] R. I. Cullather, S. M. J. Nowicki, B. Zhao, and M. J. Suarez, "Evaluation of the surface representation of the Greenland ice sheet in a general circulation model," Jour. Climate, vol. 27, no. 13, pp. 4835-4856, 2014.

[2] D. K. Hall, J. C. Comiso, N. E. DiGirolamo, C. A. Shuman, J. R. Key, and L. S. Koenig, "A satellite-derived climate-quality data record of the clear-sky surface temperature of the Greenland Ice Sheet," Jour. Climate, vol. 25, pp. 4785-4798, 2012.

[5] I. M. Howat, A. Negrete and B. E. Smith, "The Greenland Ice Mapping Project (GIMP) land classification and surface elevation data sets,"The Cryosphere vol. 8, no. 4, pp. 1509-1518, 2014.

[7] J. Key, C. Collins, C. Fowler, and R. S. Stone, "High-latitude surface temperature estimates from thermal satellite data," Remote Sens. Environ., vol. 61, pp. 302-309, 1997.

[3] S. Nowicki, and Coauthors, "Insights into spatial sensitivities of ice mass response to environmental change from the SeaRISE ice sheet modeling project II: Greenland," J. Geophys. Res. Earth Surf., vol. 118, pp. 1025-1044, doi:10.1002/jgrf.20076, 2013.
[6] M. Tedesco, S. Doherty, X. Fettweis, P. Alexander, J. Jeyaratnam, and J. Stroeve, "The darkening of the Greenland ice sheet: trends, drivers, and projections (1981-2100)," The Cryosphere, vol. 10, pp. 477-496, doi:10.5194/tc10-477-2016, 2016. 